Lucrările Seminarului Geografic Dimitrie Cantemir

Vol. 45, October 2017, pp. 81-88

http://dx.doi.org/10.15551/lsgdc.v45i0.07

\title{
Investigating the relationship between land surface temperature and urban indices using landsat-8: a case study of laşi
}

\author{
Paul Macarof ${ }^{1}$, Iulian Cristian Bîrlica' ${ }^{1}$, Florian Stătescu ${ }^{1}$ \\ ${ }^{1}$ Gheorghe Asachi Technical University of Iasi, Romania.
}

To cite this article: Macarof, P., Bîrlica, I. C. \& Stătescu, F. (2017). Investigating the relationship between land surface temperature and urban indices using landsat-8: a case study of Iaşi.

Lucrările Seminarului Geografic Dimitrie Cantemir, Vol. 45, pp. 81-88. DOI:

10.15551/lsgdc.v45i0.07

To link to this article: http://dx.doi.org/10.15551/lsgdc.v45i0.07 


\title{
INVESTIGATING THE RELATIONSHIP BETWEEN LAND SURFACE TEMPERATURE AND URBAN INDICES USING LANDSAT-8: A CASE STUDY OF IAŞI
}

\author{
Paul Macarof ${ }^{1}$, Iulian Cristian Bîrlica ${ }^{1}$, Florian Stătescu ${ }^{1}$
}

\begin{abstract}
This study investigates the relationship between land surface temperature (LST) and urban indices (such as: Normalized Difference Bareness Index (NDBaI), Normalized Difference Buildup Index (NDBI) and Urban Index (UI)) using Landsat-8 OLI imagery, for Iasi municipality area. Landsat data were used to estimate the LST, NDBI, NDBaI and UI for Iasi municipality area, between 2013-2016. In that period, the mean temperature rose by about $2^{\circ} \mathrm{C}$, so as to 2016 the mean temperature was of over $30^{\circ} \mathrm{C}$ and the maximum temperature exceeded $40^{\circ} \mathrm{C}$. Analyzing the relationship between LST and urban indices it can be noticed that, whilst NDBI and UI indices have high a correlation with LST, the correlation between NDBaI and LST is lower. The $\mathrm{R}^{2}$ fluctuates significantly from over 0.4 for NDBI and UI to about zero for NDBaI. Therefore, NDBI and UI are accurate indicators of SUHI effects, as against NDBaI and can be used as a complementary metric to the traditionally applied NDVI for analyzing surface urban heat island studies.
\end{abstract}

Keywords: Land surface temperature, urban index, Landsat-8

\section{Introduction}

Land surface temperature is an estimate of ground temperature and it is important to identify changes in the environment. Land surface temperature can provide important information on the surface physical properties and climate which plays a role in many environmental processes (Dousset, Gourmelon 2003; Weng, Lu, Schubring, 2004). Many studies have estimated the relative warmth of cities by measuring the air temperature, but this method can be both expensive and time consuming. Remote sensing is a better alternative to the aforesaid methods. The advantages of using remotely sensed data are the availability of high resolution, consistent and repetitive coverage and capability of measurements of earth surface conditions (Owen, Carlson \& Gillies 1998). Many studies showed that the surface temperature of the work confirmed from Landsat data (TM/OLI) (Amiri et al., 2009; Mallick et al., 2012; Guo et al., 2012; Li et al. 2016; Avdan et al., 2016). LST (Land Surface Temperature), used to find the change in local, regional or global scale and the temperature distribution, used in climate change models especially. Calculated from remote sensing data, LST is used in a lot of circles of science, like: forestry, climate change, hydrology,

1 “Gheorghe Asachi” Technical University of Iasi, Romania, Faculty of Hydrotechnical Engineering, Geodesy and Environmental Engineering, Str. Câmpului, Iasi, Romania, e-mail macarofpaul@yahoo.com 
oceanography, urban planning, agriculture etc. Obtaining surface temperatures, according to Orhan and using them in many analyses is important to define the problem correlated with the environment (O. Orhan et al. 2014).

It's known that between the LST and the normalized difference built-up index (NDBI) there is a strong linear relationship. The main goal of this study is to investigate the relationship between LST and the urban indices for period 2013-2016.

\section{Data and methods}

\subsection{Study Area}

The study area is geographically situated on latitude $47^{\circ} 12^{\prime} \mathrm{N}$ to $47^{\circ} 06^{\prime} \mathrm{N}$ and longitude $27^{\circ} 32^{\prime} \mathrm{E}$ to $27^{\circ} 40^{\prime} \mathrm{E}$. The largest city in eastern Romania is the seat of Iași County. Iaşi is located in the historic region of Moldavia and it has traditionally been one of the leading centres of the Romanian social, cultural, academic and artistic life. It is the "legendary city of the seven hills", namely Copou, Cetățuia, Bucium, Repedea, Șorogari, Galata, and Breazu, just like so many cities around world, one like example being Rome. Some of these hills have distinct churches perched on top, each of which warrants a different view of the city. The local climate is continental with large temperature differences between the seasons and with minimal rainfall. Iași is positioned on the Bahlui River, an affluent of Jijia that flows into the Prut River. (www.wikivoyage.org).

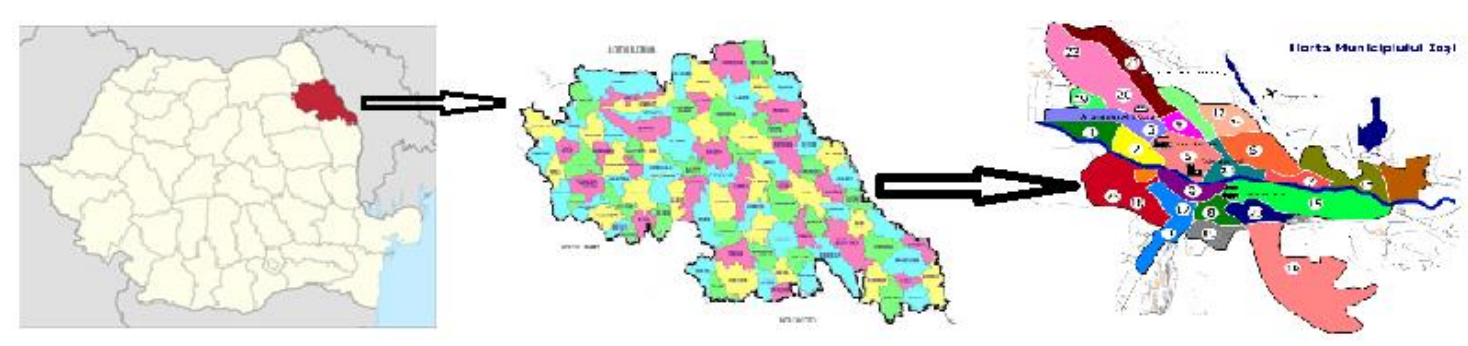

Figure 1. Study Area (www.hih.ro, www.apavital.ro)

\subsection{Data and methods}

The main objective of this study was to compare the relationships of LST and urban indices using Landsat data for the period 2013-2016 using Iasi metropolitan area as a case study.

Landsat 8 measures different ranges of frequencies along the electromagnetic spectrum - a color, despite not necessarily a color visible to the human eye. Each range is called a band, and Landsat 8 has 11 bands. The last bands, the tenth and eleventh are in the thermal infrared (TIR) - they see heat. Instead of measuring the temperature of the air, these report on the ground itself, which is often much hotter (N.A.S.A. Landsat Science).

Landsat data were offered free by USGS. Table 1 shows Landsat data that was used in this research. 
Table 1. Landsat data

\begin{tabular}{|c|c|c|c|}
\hline Nr. Crt. & Path & Row & Date \\
\hline 1 & 182 & 27 & $2013-08-13$ \\
\hline 2 & 182 & 27 & $2014-07-31$ \\
\hline 3 & 182 & 27 & $2015-07-18$ \\
\hline 4 & 182 & 27 & $2016-08-05$ \\
\hline
\end{tabular}

\subsection{Data processing}

The widespread and common urban indices are shown in the Table 2. The most of these indices extract urbanization parameters related to spectral difference of visible, near infrared and short wave infrared bands of Landsat 8 Imagery.

Zhao, in 2003, utilized Landsat 7 band 6 (TIR) and band 5 (SWIR) to generate the NDBaI. This is an index used to map bare land areas. Thermal infrared bands can distinguish high and low levels of albedo in built-up objects (Zhao et al., 2003). According to Weng, in 2008, the utilization of TIR bands is very efficient for mapping built-up areas based on a low albedo, who eliminates the effect of water and shadows, while a high albedo demonstrates bare land and built-up areas clearly.

Zha et al., in 2003, proposed a NDBI (Normalized Difference Built-up Index) to map the urban built-up area. In conjunction with a traditional NDVI (Normalized Difference Vegetation Index), this index was reported to be an effective technique to map urban built-up area. NDBI had a total accuracy $92 \%$ in their study area.

Remote sensing can be used to acquire a description of the building density with a spectral transformation called urban index transformation (Kawamura et. al., 1996). Was demonstrated that high pixel value indicates built-up area intensively.

Table 2. Urban Indices

\begin{tabular}{|c|c|c|}
\hline No. & Name of urban index & Formulation \\
\hline 1 & $\begin{array}{c}\text { Normalized Difference Bareness } \\
\text { Index (NDBaI) }\end{array}$ & NDBaI $=\frac{S W I R_{1}-T I R S_{1}}{S W I R_{1}+T I R S_{1}}$ \\
\hline 2 & $\begin{array}{c}\text { Normalized Difference Build-Up } \\
\text { (NDBI) }\end{array}$ & $\mathrm{NDBI}=\frac{S W I R_{1}-N I R}{S W I R_{1}+N I R}$ \\
\hline 3 & Urban Index (UI) & $\mathrm{UI}=\frac{S W I R_{2}-N I R}{S W I R_{2}+N I R}$ \\
\hline
\end{tabular}

\section{RESLUTS AND DISCUSSION}

\subsection{LST and urban indices spatial patterns}

Figure 2 shows LST maps for the period 2013-2016 and table 3 shows the statistical data of LST. Analyzing parameters: variation and mean show a raise of temperature for the 
period 2013-2016, of about of $2^{\circ} \mathrm{C}$. Parameters mean shows, just for 2015, a little decrease as against 2014, but temperature increases in 2016.

Table 3. Statistical data of LST

\begin{tabular}{|c|c|c|c|c|c|}
\hline Years & Minimum & Maximum & Variations & Mean & $\begin{array}{c}\text { Standard } \\
\text { Deviation }\end{array}$ \\
\hline 2013 & 22.95 & 38.20 & 15.25 & 28.73 & 2.017 \\
\hline 2014 & 23.80 & 39.98 & 16.18 & 29.53 & 2.142 \\
\hline 2015 & 23.30 & 39.10 & 15.80 & 29.34 & 1.908 \\
\hline 2016 & 24.51 & 40.78 & 16.27 & 30.13 & 1.961 \\
\hline
\end{tabular}

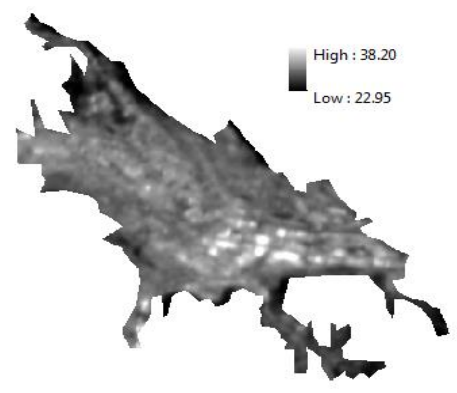

2013

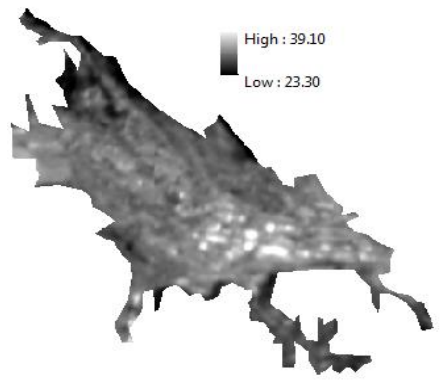

2015

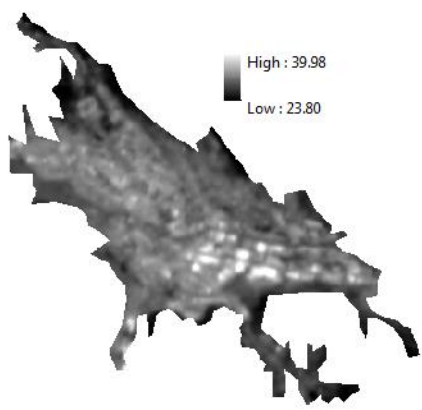

2014

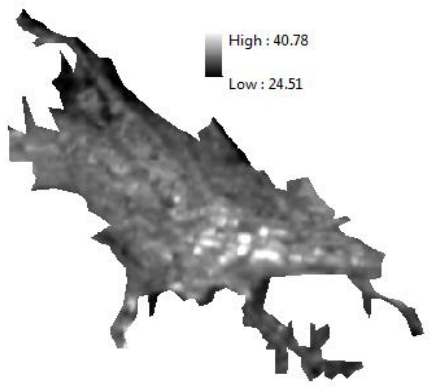

2016

Figure 2. LST maps for period 2013-2016

\subsection{LST relationships to urban indices}

By analyzing the primary parameter mean, we see that the changes of the urban indices for the period 2013-2016 are minor. Parameter variations in 2015 and 2016 are determined by the emergence of new areas of construction. The value of parameter mean for UI is of about 1 in 2015 and 2016. The increasing value of the parameter mean demonstrates that the municipality of Iasi is a rapidly growing area and the emergence of new sites increases LST values. This is favored by the fact that there are few green spaces in the city of Iasi. 
Figure 3 shows the urban indices maps and table 4 shows the statistical data of the indices for the period 2013-2016.

Table 4. Statistical data of urban indices

\begin{tabular}{|c|c|c|c|c|c|c|c|c|c|c|c|c|}
\hline \multirow[t]{2}{*}{ Years } & \multicolumn{3}{|c|}{2013} & \multicolumn{3}{|c|}{2014} & \multicolumn{3}{|c|}{2015} & \multicolumn{3}{|c|}{2016} \\
\hline & $\begin{array}{l}\mathrm{ND} \\
\mathrm{BaI}\end{array}$ & $\begin{array}{c}\text { NDB } \\
\text { I }\end{array}$ & UI & $\begin{array}{l}\mathrm{ND} \\
\mathrm{BaI}\end{array}$ & $\begin{array}{c}\text { ND } \\
\text { BI }\end{array}$ & UI & $\begin{array}{c}\text { NDBa } \\
\text { I }\end{array}$ & $\begin{array}{c}\mathrm{ND} \\
\mathrm{BI}\end{array}$ & UI & $\begin{array}{c}\text { NDB } \\
\text { aI }\end{array}$ & $\begin{array}{c}\text { ND } \\
\text { BI }\end{array}$ & UI \\
\hline Min. & $\begin{array}{c}- \\
0.6 \\
5\end{array}$ & -0.38 & 0.55 & $\begin{array}{c}- \\
0.63\end{array}$ & $\begin{array}{c}- \\
0.36\end{array}$ & $\begin{array}{c}- \\
0.53\end{array}$ & -0.63 & $\begin{array}{c}- \\
0.37\end{array}$ & 0.55 & -0.63 & $\begin{array}{c}- \\
0.38\end{array}$ & $\begin{array}{c}- \\
0.56\end{array}$ \\
\hline Max. & 0.2 & 0.34 & 0.33 & 0.33 & 0.41 & 0.32 & 0.26 & 0.45 & 0.45 & 0.34 & 0.42 & 0.44 \\
\hline Var. & $\begin{array}{c}0.8 \\
5\end{array}$ & 0.72 & 0.88 & 0.96 & 0.77 & 0.85 & 0.89 & 0.82 & 1 & 0.97 & 0.8 & 1 \\
\hline Mean & -0.4 & -0.09 & -0.2 & -0.4 & $\begin{array}{c}- \\
0.09\end{array}$ & -0.2 & -0.38 & $\begin{array}{c}- \\
0.09\end{array}$ & -0.2 & -0.39 & $\begin{array}{c}- \\
0.08\end{array}$ & $\begin{array}{c}- \\
0.18\end{array}$ \\
\hline $\begin{array}{c}\text { St. } \\
\text { Dev. }\end{array}$ & $\begin{array}{c}0.0 \\
5\end{array}$ & 0.08 & 0.11 & 0.05 & 0.08 & 0.11 & 0.05 & 0.08 & 0.11 & 0.06 & 0.08 & 0.11 \\
\hline
\end{tabular}
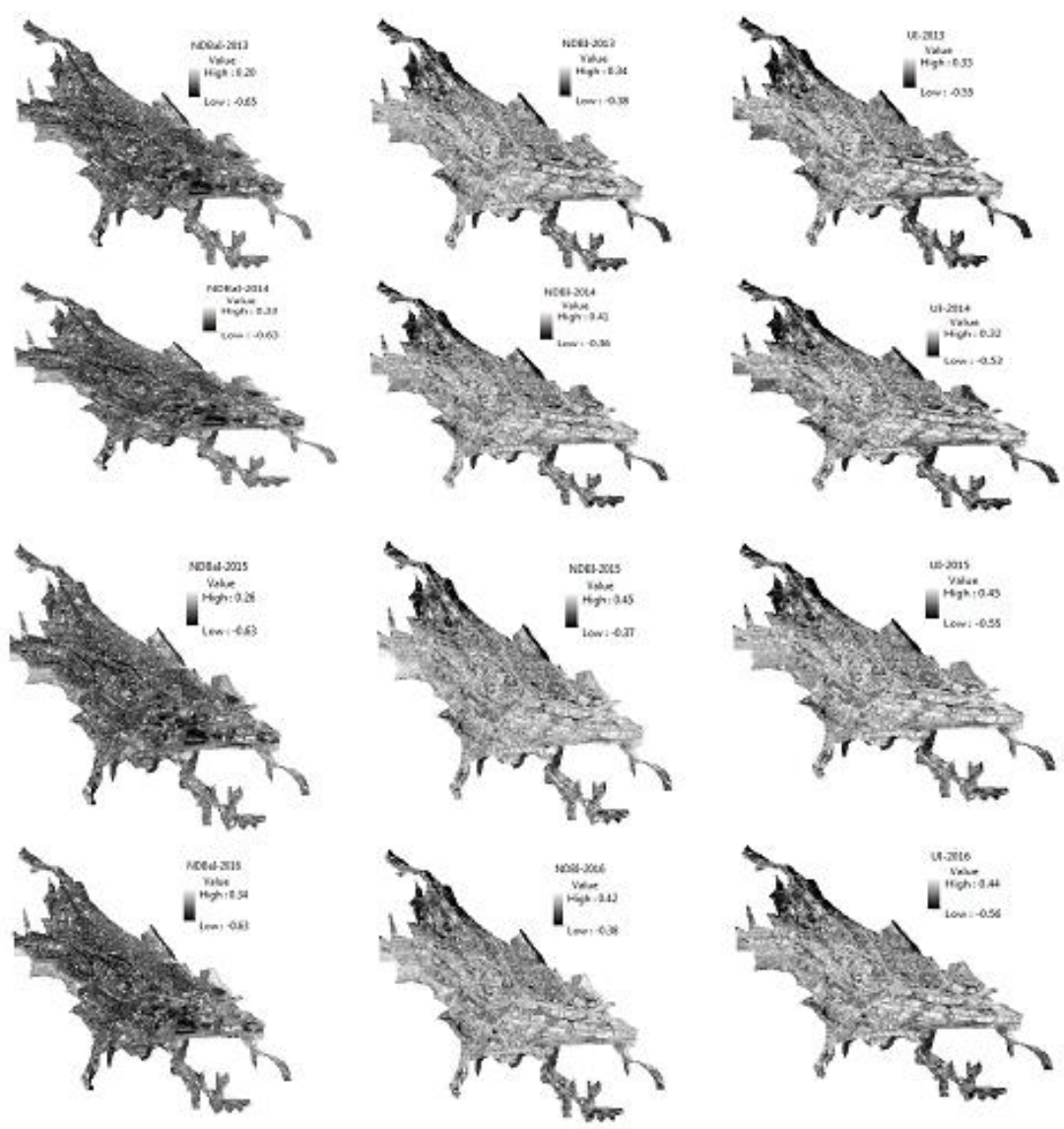

Figure 3. Urban indices maps for period 2013-2016 
Figure 4 shows the relationship of LST and urban indices for period 2013-2016.

By analyzing the relationship between LST and the urban indices we notic that, whilst NDBI and UI indices have high correlation with LST, there is a lower correlation with NDBaI. The $\mathrm{R}^{2}$ fluctuates significantly from over 0.4 for NDBI and UI to about zero for NDBaI.

We see that with the increasing "mean" parameter value of the index NDBaI, there appears a slight decrease in the value of $\mathrm{R}^{2}$ coefficient of linear function. The strongest correlation between LST and UI is in 2013 when $\mathrm{R}^{2}$ is about of 0.53 , while the highest value of $\mathrm{R}^{2}$ for relationship LST-NDBI is 0.49 in 2015
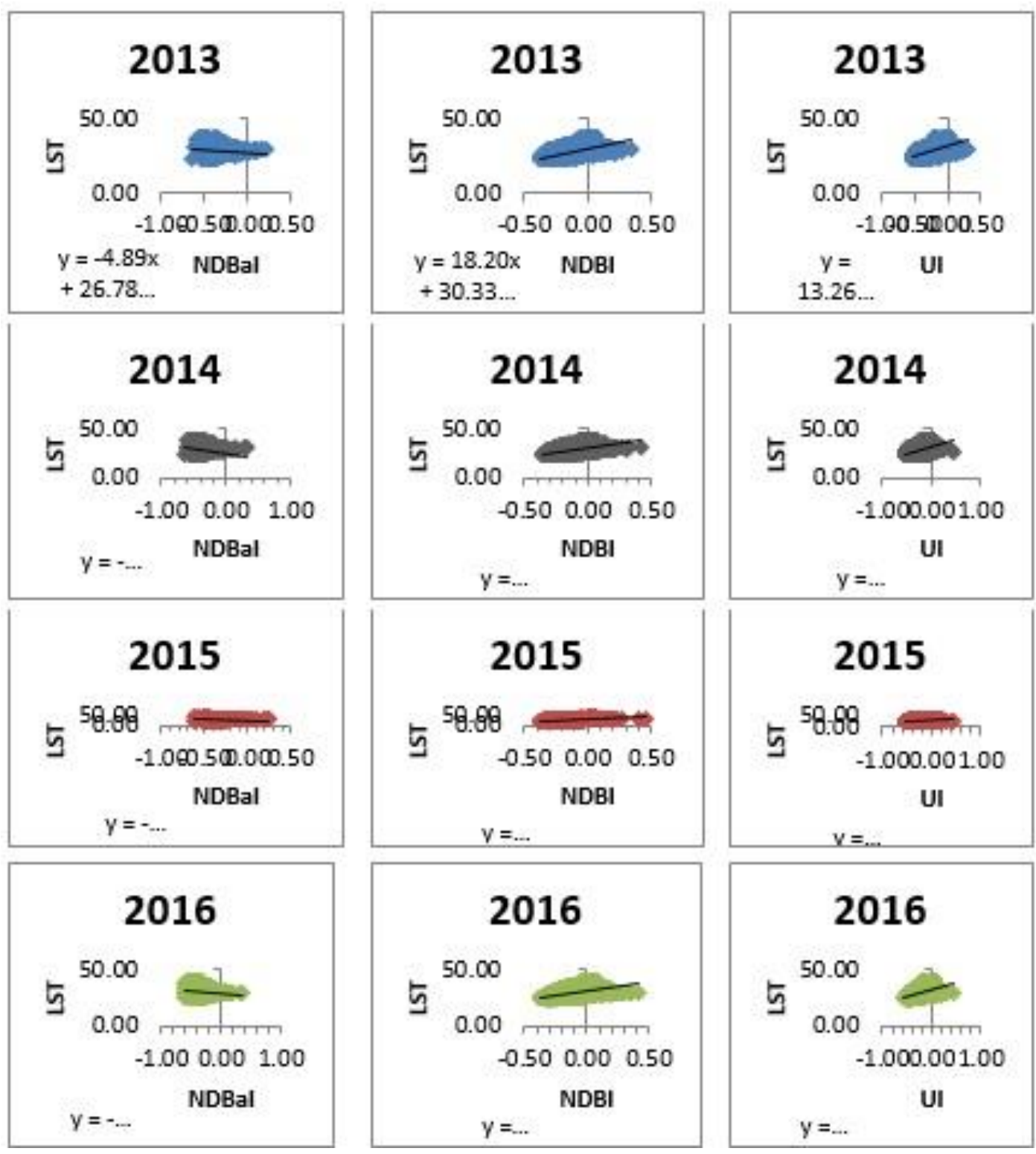

Figure 4. Relationship of LST and urban indices for period 2013-2016 


\section{Conclusions}

This paper investigated the relationships between LST and urban indices such as: NDBaI, NDBI and UI, for period 2013-2016 for Iaşi municipality area. In the same period a rise of the mean temperature of about of $2^{\circ} \mathrm{C}$ was recorded.

The results indicate there is a strong linear relationship between LST and urban indices (UI and NDBI), whilst the correlation between LST and NDBaI is lower. The $\mathrm{R}^{2}$ fluctuates significantly from over 0.4 for NDBI and UI to about zero for NDBaI. Therefore, NDBI and UI are accurate indicators of SUHI effects, as against NDBaI and can be used as a complementary metric to the traditionally applied NDVI for analyzing surface urban heat island studies.

While we found the variations in surface temperature can be better explained by NDBI and UI than by NDBaI, we also realize that the conclusion is based on only one area, so further are recommended other studies for other metropolitan areas.

\section{References}

1. Amiri R., Weng Q., Alimohammadi A., Alavipanah S., 2009. Spatial-temporal dynamics of LST in relation to fractional vegetation cover and LU/LC in the Tabriz urban area, Iran. doi: https://www.researchgate.net.

2. Avdan U., Jovanovska Gr., 2016 Algorithm for automated mapping of LST using LANDSAT 8 satellite data. doi: http://dx.doi.org/10.1155/2016/1480307.

3. Dousset B., Gourmelon F., 2003, Satellite multi-sensor data analysis of urban surface temperatures and landcover. Doi: https://doi.org/10.1016/S0924-2716(03)00016-9

4. Guo Z., Wang S., Cheng M., Y, Shu, 2012. Assess the effect of different degrees of urbanization on LST using remote sensing images. doi: https://doi.org/10.1016/j.proenv.2012.01.087

5. Kawamura K., R. Sempe're', Y. Imai, Y. Fujii, M. Hayashi, 1996, Water soluble dicarboxylic acids and related compounds in Antarctic aerosols, J. Geophys. Doi: 10.1029/96JD01541

6. Mallick J., Singh C., Shashtri S., Rahman A., Mukherjee S., 2012, LSE retrieval based on moisture index from LANDSAT TM satellite data over heterogeneous surfaces of Delhi city. Doi: https://doi.org/10.1016/j.jag.2012.06.002

7. Orhan O., Yakar M., 2016, Investigating Land Surface Temperature Changes Using Landsat Data in Konya, Turkey doi: doi: https://www.academia.edu

8. Orhan, O., Ekercin, S., Dadaser-Celik, F., 2014 Use of Landsat LST and Vegetation Indices for Monitoring Drought in the Salt Lake Basin Area, Turkey, doi:10.1155/2014/142939

9. Owen, T., Carlson, T., Gillies, R., 1998. An Assessment of Satellite Remotely Sensed Land Cover Parameters in Quantitatively Describing the Climatic Effect of Urbanization.

10. Weng Q., Lu D., Schubring J., 2004. Estimation of land surface temperature-vegetation abundance relationship for urban heat island studies. DOI: 10.1016/j.rse.2003.11.005

11. Weng, Q., Hu, X., Lu, D. 2008. Extracting impervious surface from medium spatial resolution multispectral and hyperspectral imagery: A comparison. doi:10.1080/01431160701469024.

12. Xiaoxiao Li, Wenwen Li, A. Middel, S. Harlan, A. Brazel, Turner B., 2012. Remote sensing of the SUHI and land architecture in Phoenix, Arizona: Combined effects of land composition and configuration and cadastral-demographic-economic factors, doi: https://doi.org/10.1016/j.rse.2015.12.022

13. Zha, Gao, Li, 2003, Use of normalized difference built-up index (NDBI) in automatically mapping urban areas from TM imager. Doi: 10.1080/01431160304987

*** NASA Landsat Science (https://landsat.gsfc.nasa.gov)

*** www.hih.ro 
*** www.apavital.ro

*** www.wikivoyage.org 